\title{
CGK062, a small chemical molecule, inhibits cancer upregulated gene 2 -induced oncogenesis through NEK2 and $\beta$-catenin
}

\author{
SIRICHAT KAOWINN ${ }^{1 *}$, SANGTAEK OH $^{2 *}$, JEONG MOON $^{1}$, AH YOUNG YOO $^{3}$, \\ HO YOUNG KANG ${ }^{3}$, MI RIM LEE ${ }^{4}$, JI EUN KIM ${ }^{4}$, DAE YOUN HWANG ${ }^{4}$, \\ SO EUN YOUN ${ }^{5}$, SANG SEOK $\mathrm{KOH}^{5}$ and YOUNG-HWA CHUNG ${ }^{1}$ \\ ${ }^{1}$ BK21 Plus, Department of Cogno-Mechatronics Engineering, Pusan National University, Busan 46241; \\ ${ }^{2}$ Department of Bio and Fermentation Convergence Technology, Kookmin University, Seoul 02707; ${ }^{3}$ Department of \\ Microbiology, Pusan National University, Busan 46241; ${ }^{4}$ Department of Biomaterials, Pusan National University, \\ Miryang 50463; ${ }^{5}$ Department of Biosciences, Dong-A University, Busan 49315, Republic of Korea
}

Received August 20, 2018; Accepted February 4, 2019

DOI: $10.3892 /$ ijo.2019.4724

\begin{abstract}
The mechanisms through which cancer-upregulated gene 2 (CUG2), a novel oncogene, affects $\mathrm{Wnt} / \beta$-catenin signaling, essential for tumorigenesis, are unclear. In this study, we aimed to elucidate some of these mechanisms in A549 lung cancer cells. Under the overexpression of CUG2, the protein levels and activity of $\beta$-catenin were evaluated by western blot analysis and luciferase assay. To examine a biological consequence of $\beta$-catenin under CUG2 overexpression, cell migration, invasion and sphere formation assay were performed. The upregulation of $\beta$-catenin induced by CUG 2 overexpression was also accessed by xenotransplantation in mice. We first found that CUG2 overexpression increased $\beta$-catenin expression and activity. The suppression of $\beta$-catenin decreased cancer stem cell (CSC)-like phenotypes, indicating that $\beta$-catenin is involved in CUG2-mediated CSC-like phenotypes. Notably, CUG2 overexpression increased the phosphorylation of $\beta$-catenin at Ser33/Ser37, which is known to recruit E3 ligase for $\beta$-catenin degradation. Moreover, CUG2 interacted with and enhanced the expression and kinase activity of never in mitosis gene A-related kinase 2 (NEK2). Recombinant NEK2 phosphorylated $\beta$-catenin at Ser33/Ser37, while NEK2 knockdown decreased the phosphorylation of $\beta$-catenin, suggesting that NEK2 is involved in the phosphorylation of $\beta$-catenin at Ser33/Ser37. Treatment with CGK062, a small chemical molecule, which promotes the phosphorylation of $\beta$-catenin at Ser33/Ser37 through protein
\end{abstract}

Correspondence to: Professor Young-Hwa Chung, BK21 Plus, Department of Cogno-Mechatronics Engineering, Pusan National University, 2 Busandaehak-ro 63 Beon-gil, Geumjeong-gu, Busan 46241, Republic of Korea

E-mail: younghc@pusan.ac.kr

*Contributed equally

Key words: cancer-upregulated gene 2, cancer stem cell, never in mitosis gene A-related kinase 2, $\beta$-catenin, CGK062 kinase $\mathrm{C}$ (PKC) $\alpha$ to induce its degradation, reduced $\beta$-catenin levels and inhibited the CUG2-induced features of malignant tumors, including increased cell migration, invasion and sphere formation. Furthermore, CGK062 treatment suppressed CUG2-mediated tumor formation in nude mice. Taken together, the findings of this study suggest that CUG2 enhances the phosphorylation of $\beta$-catenin at Ser33/Ser37 by activating NEK2, thus stabilizing $\beta$-catenin. CGK062 may thus have potential for use as a therapeutic drug against CUG2-overexpressing lung cancer cells.

\section{Introduction}

Cancer upregulated gene 2 (CUG2), a candidate oncogene, is commonly upregulated in various types of cancer, including ovarian, liver, colon and lung cancers, and plays a crucial role in tumorigenesis (1). Some studies have identified CUG2 as a novel centromeric component required for appropriate kinetochore functioning during cell division $(2,3)$. In a previous study, in an NIH3T3 cell transplantation model, CUG2 was found to exert an oncogenic effect similar to that of mutant Ras (1). CUG2 overexpression activates Ras and mitogen-activated protein kinases (MAPKs), including p38 MAPK, which facilitates oncolytic retroviral replication (4). CUG2 has been suggested to induce epithelial-mesenchymal transition (EMT) through transforming growth factor (TGF)- $\beta$ signaling (5). A recent study reported that CUG2 enhanced epidermal growth factor receptor (EGFR) expression to induce doxorubicin resistance by activating the signal transducer and activator of transcription 1 (Stat1)/histone deacetylase 4 (HDAC4) signaling axis, which involves the TGF- $\beta$ signaling pathway (6).

The Wnt/ $\beta$-catenin signaling pathway plays an important role in cell proliferation, differentiation and oncogenesis $(7,8)$. Particularly, the abnormal upregulation of $\mathrm{Wnt} / \beta$-catenin activity is frequently detected as an early event in a number of types of cancer (9). The Wnt signal is initiated by the interaction of Wnt proteins (Wnt1, Wnt3a and Wnt8) with the Frizzled receptor and low-density lipoprotein receptor-related protein $5 / 6$ coreceptors (9). This signal is then transduced through disheveled protein to negatively regulate glycogen 
synthase kinase $3 \beta$ (GSK3 $\beta$ ), which results in the cytoplasmic accumulation of $\beta$-catenin. The accumulated $\beta$-catenin is then translocated into the nucleus where it complexes with $\mathrm{T}$ cell factor/lymphocyte enhancer factor (TCF/LEF) family of transcription factors to activate the expression of $\beta$-catenin-responsive genes such as cyclin D1, c-Jun, c-Myc and peroxisome proliferator-activated receptor- $\delta$ (10-13). A number of types of cancer exhibit the accumulation of $\beta$-catenin and the consequent activation of TCF/LEF-dependent gene transcription (14-16).

In quiescent cells, $\beta$-catenin is maintained in the cytoplasm at low levels. This is facilitated by its interaction with scaffolding proteins, such as adenomatous polyposis coli and axin, and with protein kinases, such as casein kinase 1a and GSK3 $\beta$, which phosphorylate $\beta$-catenin at Ser45 and Ser33/Ser37/Thr41, respectively, leading to its ubiquitination and proteasomal degradation (17-19). Wnt and other growth stimuli induce GSK3 $\beta$ phosphorylation, resulting in the inactivation of $\beta$-catenin phosphorylation at Ser33/Ser37/Thr41, its stabilization, and its subsequent translocation to the nucleus (20). Previous studies have demonstrated that protein kinase A (PKA) also stabilizes $\beta$-catenin by phosphorylating it at $\operatorname{Ser675}(21,22)$.

The present study examined whether the overexpression of CUG2, a novel oncogene, affects the Wnt/ $\beta$-catenin signaling pathway, which is essential for tumorigenesis. We found that CUG2 overexpression increased $\beta$-catenin activity and stability, which was regulated by never in mitosis gene A-related kinase 2 (NEK2). Treatment with CGK062 targeting $\beta$-catenin through PKC $\alpha$ inhibited CUG2-induced cancer stem cell (CSC)-like phenotypes, thus impairing tumor formation in vivo. Taken together, the findings of this study provide new evidence to suggest that CUG2 overexpression contributes to tumor formation through NEK $2 / \beta$-catenin signaling.

\section{Materials and methods}

Cell culture and CUG2 plasmid construction. Human lung cancer-derived A549 cells were obtained from the American Type Culture Collection (ATCC, Manassas, VA, USA). As previously described (1), cDNA of CUG2 was inserted into the pCDNA3.1/Myc-His vector (Invitrogen/Thermo Fisher Scientific, Waltham, MA, USA) using the BamHI and XhoI sites. A549 parental cells was transfected with pCDNA3.1/Myc-His vector or pCDNA3.1/Myc-His-CUG2 using Lipofectamine 2000 (Invtrogen/Thermo Fisher Scentific). Cells stably expressing the vector alone (A549-VEC) or wild-type CUG2 (A549-CUG2) were selected under 1,000 $\mu \mathrm{g} / \mathrm{ml}$ G418 (Sigma-Aldrich, St. Louis, MO, USA) for 30 days and maintained in RPMI-1640 medium supplemented with $10 \% \mathrm{FBS}, 1 \%$ penicillin, $1 \%$ streptomycin and $500 \mu \mathrm{g} / \mathrm{ml}$ $\mathrm{G} 418$ at $37^{\circ} \mathrm{C}$ in a humidified atmosphere of $5 \% \mathrm{CO}_{2}$.

Reagents and antibodies. Anti-NEK2 antibodies (610593) for used in western blot analysis and immunofluorescence microscopywere purchased from BD Biosciences (San Jose, CA, USA) and those (sc-55601) for performing NEK2 kinase assay were purchased from Santa Cruz Biotechnology (Santa Cruz, CA, USA). Anti-ALDH1 antibodies (611194) were acquired from BD Biosciences. Antibodies against Smad2/3 (\#5678), phosphorylated Smad2 (\#3108), $\beta$-catenin (\#9562), and phosphorylated $\beta$-catenin (Ser33/Ser37/Thr41, Ser45, or Ser675; \#9561, \#9564, or \#4176, respectively) were purchased from Cell Signaling Biotechnology (Danvers, MA, USA). Antibodies against E-cadherin (ab15148), N-cadherin (ab18203), vimentin, Snail (ab180714), Twist (ab175430), Bmi1 (ab126783), Sox2 (ab97959), octamer-binding transcription factor 4 (Oct4; ab109183), Kruppel-like factor 4 (K1f4; ab129473) and Nanog (ab109250) were obtained from Abcam (Cambridge, MA, USA). Anti- $\beta$-actin antibody (sc-4778) and anti-Sp1 antibody (sc-17824) were obtained from Santa Cruz Biotechnology, and wortmannin, MG132, H89, PP2 and bisindolylmaleimide I (BMI) were purchased from Calbiochem (San Diego, CA, USA). Wnt3a was purchased from R\&D Systems Inc. (Minneapolis, MN, USA). CGK062 was prepared as previously described (23).

Cellular fractionation. As previously described (24), cells cultured in 100-mm plates were washed and harvested with ice-cold PBS and cell pellets were lysed in $800 \mu 1$ TTN buffer [20 mM Tris- $\mathrm{HCl}$ (pH 7.4), 0.05\% Triton X-100, $150 \mathrm{mM}$ $\mathrm{NaCl}, 1 \mathrm{mM}$ EDTA, $1 \mathrm{mM}$ DTT, 10\% glycerol, $0.5 \mathrm{mM}$ PMSF and 1X protease inhibitor cocktail] on ice for $20 \mathrm{~min}$, followed by centrifugation at $10,000 \mathrm{x} \mathrm{g}$ for $15 \mathrm{~min}$. The supernatant obtained was used as a soluble fraction. Pellets, which were used as an insoluble fraction, were solubilized in $800 \mu$ l RIPA buffer [50 mM Tris- $\mathrm{HCl}(\mathrm{pH} 7.4), 150 \mathrm{mM}$ $\mathrm{NaCl}, 1$ mM EDTA, 1 mM DTT, 1\% NP-40, 0.5\% deoxycholic acid, $0.1 \%$ SDS, $10 \%$ glycerol, $0.5 \mathrm{mM}$ PMSF and $1 \mathrm{X}$ protease inhibitor cocktail] on ice for $30 \mathrm{~min}$ and were centrifuged at $12,000 \mathrm{x} g$ for $15 \mathrm{~min}$. Thereafter, the supernatants were used for the nuclear extracts.

Western blot analysis and immunoprecipitation. Cells were harvested and lysed in a lysis buffer containing $1 \%$ NP-40 and protease inhibitors (Sigma-Aldrich). For performing western blot analysis, proteins from whole cell lysates were resolved by performing SDS-PAGE (10\% or $12 \%$ gel) and were transferred onto nitrocellulose membranes. Primary antibodies were used at a dilution of 1:1,000 or 1:2,000, and horseradish peroxidase-conjugated goat anti-mouse (12-349; Merck-Millipore, Billerica, MA, USA) or anti-rabbit (12-348; Merck-Millipore) antibodies were used at a dilution of 1:2,000 in 5\% non-fat dry milk. After washing, the membranes were examined by performing an enhanced chemiluminescence assay by using Image Quant LAS 4000 Mini (GE-Healthcare, Tokyo, Japan). For immunoprecipitation, cells were harvested after $48 \mathrm{~h}$ of transfection, and the cell debris was removed by centrifugation at $10,000 \mathrm{x}$ g for $10 \mathrm{~min}$ at $4^{\circ} \mathrm{C}$. Cell lysates were pre-cleared with $25 \mu \mathrm{l}$ of protein $\mathrm{A} / \mathrm{G}$ agarose and incubated with the appropriate primary antibody and protein $\mathrm{A} / \mathrm{G}$ agarose for $1 \mathrm{~h}$ at $4^{\circ} \mathrm{C}$. Following 3 washes with lysis buffer, the precipitates were resolved on SDS-PAGE gels and analyzed by immunoblotting with the appropriate antibodies.

siRNA transfection. Before performing siRNA transfection, the cells were trypsinized and cultured overnight to achieve $60-70 \%$ confluence. Subsequently, the cells were incubated with a transfection mixture containing premade $\beta$-catenin, NEK2 
and GSK3 $\beta$ and PKC $\alpha$ siRNAs (Bioneer, Daejeon, Korea) or a negative control siRNA (Bioneer) and Lipofectamine 2000 (Invitrogen/Thermo Fisher Scientific) for $6 \mathrm{~h}$, rinsed with a medium containing $10 \% \mathrm{FBS}$, and incubated at $37^{\circ} \mathrm{C}$ for $48 \mathrm{~h}$ before harvesting. To confirm the effect of the silencing protein levels, two types of premade siRNAs were used.

Reverse transcription-polymerase chain reaction (RT-PCR). For performing RT-PCR, total RNA was extracted from the cells using an RNeasy protect cell mini kit (Qiagen, Valencia, CA, USA), in accordance with the manufacturer's instructions. Subsequently, $3 \mu \mathrm{g}$ total RNA were reversed transcribed into cDNA using Superscript II reverse transcriptase (Invitrogen/Thermo Fisher Scientific). PCR was performed using specific primers described elsewhere $(25,26)$. cDNAs obtained for each sample were diluted, and PCR was performed using an optimized cycle number. $\beta$-actin mRNA was used as an internal standard. The relative ratio of $\beta$-catenin and $\beta$-actin mRNA levels was expressed after measuring band intensity with Multi Gauge Ver. 2.1 (Fuji Photo Film, Japan).

Immunofluorescence microscopy. For performing immunofluorescence microscopy, cells grown on coverslips were fixed with $4 \%$ paraformaldehyde for $15 \mathrm{~min}$, permeabilized with cold acetone for $15 \mathrm{~min}$, blocked with $10 \%$ goat serum for $30 \mathrm{~min}$, and treated with anti-NEK2 and anti-phosphorylated $\beta$-catenin antibodies (Ser33/Ser37/Thr41; dilution, 1:100) for $30 \mathrm{~min}$ at room temperature. Following incubation, the cells were washed extensively with PBS, incubated with Alexa Fluor 488-conjugated goat anti-rabbit antibody (A11008) and Alexa Fluor 594-conjugated goat anti-mouse antibody (A11005) (dilution, 1:500; Thermo Fisher Scientific), respectively, in PBS for $30 \mathrm{~min}$ at room temperature; and washed 3 times with PBS. For performing nuclear staining, the cells were incubated with 4',6-diamidino-2-phenylindole (DAPI) for $5 \mathrm{~min}$ in the dark and were washed 3 times with PBS. Subsequently, coverslips with stained cells were mounted on slides by using PBS containing $10 \%$ glycerol and were imaged using a fluorescence microscope (Zeiss Axio Observer D1, Oberkochen, German).

Luciferase reporter assays. A549-CUG2 cells were transfected with TGF- $\beta$ promoter (phTG5 and 7) (27), Top-Flash (containing 2 sets of 3 copies of the TCF binding sites), or Fop-Flash (carrying the mutated TCF binding sites) vectors using Lipofectamine 2000. To normalize the transfection efficiency, a pGK- $\beta$ gal vector expressing $\beta$-galactosidase under the control of the phosphoglucokinase promoter was included in the transfection mixture. At $48 \mathrm{~h}$ after the transfection, the cells were washed with cold PBS and lysed in a lysis solution [25 mM Tris ( $\mathrm{pH} 7.8$ ), 2 mM EDTA, 2 mM DTT, 10\% glycerol and 1\% Triton X-100] and the luciferase activity was measured using a luminometer and luciferase kit (Promega, Madison, WI, USA).

Invasion assay. Invasion assays were performed using 48-well Boyden chambers (Neuroprobe, Gaithersburg, MD, USA), as previously described (28). Lower wells of the chamber were filled with a standard culture medium. The chamber was assembled using polycarbonate filters (Neuroprobe) coated with Matrigel. Cells cultured in a serum-free medium $\left(5 \times 10^{4}\right.$ cells/well) were seeded in the upper compartment of the chamber and were incubated at $37^{\circ} \mathrm{C}$ for $24 \mathrm{~h}$. The cells that invaded through the membrane were fixed with methanol (cat. no. 34860; Sigma-Aldrich) for $10 \mathrm{~min}$ at room temperature, followed by staining with hematoxylin (cat. no. HHS16, Sigma-Aldrich) for $10 \mathrm{~min}$. Subsequently, the cells were counterstained with eosin (cat. no. HT110132; Sigma-Aldrich) for $15 \mathrm{sec}$. Cell migration was quantified by counting the number of migrated cells under a phase-contrast microscope (CKX31-11PHP; Olympus, Tokyo, Japan).

Wound healing assay. Cell migration was assessed by performing a wound healing assay, as previously described (29). Briefly, the cells were cultured in 6-well plates ( $5 \times 10^{5}$ cells/well). When the cells reached $90 \%$ confluence, a single wound was created in the center of the cell monolayer using a P-200 pipette tip. At 0 and $24 \mathrm{~h}$ following incubation at $37^{\circ} \mathrm{C}$, wound closure areas were visualized using a phase-contrast microscope (CKX31-11 PHP; Olympus) at x100 magnification.

Sphere formation assay. Cells were cultured in 24-well ultra-low attachment plates in a serum-free medium supplemented with $5 \mu \mathrm{g} / \mathrm{ml}$ insulin, $0.4 \%$ bovine serum albumin, $10 \mathrm{ng} / \mathrm{ml}$ basic fibroblast growth factor and $20 \mathrm{ng} / \mathrm{ml}$ human recombinant EGF for 6 days. The size and number of spheroids formed were analyzed using a light microscope (CKX31-11 PHP; Olympus). Sphere formation was determined by counting the number of spheroids with a size of $>50 \mu \mathrm{m}$ using NIS-Element F3.0 program (Nikon, Tokyo, Japan).

NEK2 kinase assay. Cell lysates were pre-cleared with $25 \mu 1$ protein $\mathrm{A} / \mathrm{G}$ agarose and were incubated with anti-NEK2 antibody and protein $\mathrm{A} / \mathrm{G}$ agarose for $1 \mathrm{~h}$ at $4^{\circ} \mathrm{C}$. After washing 3 times with a lysis buffer, precipitates obtained were used for detecting NEK2. A reaction mixture containing the NEK2-containing immunocomplex $(15 \mu \mathrm{l})$, recombinant GST- $\beta$-catenin $(1 \mu 1,1 \mathrm{mg} / 1 \mathrm{ml}$; Sino Biological Inc., Beijing, China), $10 \mathrm{mM}$ ATP (2 $\mu \mathrm{l}$; Sigma-Aldrich), and reaction buffer [2 $\mu 1,10 \mathrm{X} ; 100 \mathrm{mM}$ Tris-acetate (pH 7.5), $100 \mathrm{mM} \mathrm{MgCl}$, $500 \mathrm{mM} \mathrm{NaCl}$ and $10 \mathrm{mM}$ DTT] was incubated at $30^{\circ} \mathrm{C}$ for $1 \mathrm{~h}$. The reaction was terminated using SDS loading buffer, and the reaction mixture was loaded onto a $10 \%$ SDS-polyacrylamide gel. The phosphorylation of GST- $\beta$-catenin at Ser33/Ser37 was determined by performing western blot analysis with a corresponding antibody.

Animal experiments. All animal experiments were conducted in accordance with the Laboratory Animal Resources Guide for the Care and Use of Laboratory Animals. All animal study protocols were approved by the Pusan National University Animal Care and Use Committee (PNU-2017-1541). Balb/C nude mice (12 mice in total; 6 male and 6 female, 4 weeks old, weighing 18-20 g) were purchased from Orient Bio Inc. (Seongnam, Korea) and were maintained under specific pathogen-free conditions (a 12-h light/12-h dark cycle, at $22^{\circ} \mathrm{C}$, and $50-55 \%$ humidity with free access to diet and tap water). Subsequently, A549-CUG2 cells $\left(1 \times 10^{6}\right.$ cells/mouse, $0.1 \mathrm{ml}$ suspension in $50 \% \mathrm{PBS}$ and $50 \%$ Matrigel; Corning, Bedford, MA, USA) were subcutaneously injected into the right flanks of the mice, and the mice were divided into 2 groups (6 mice/group). At 3 days following 

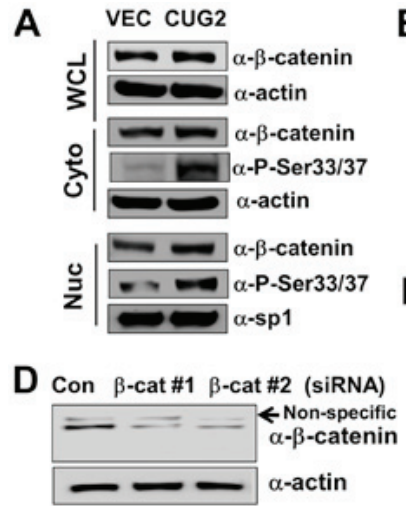

E

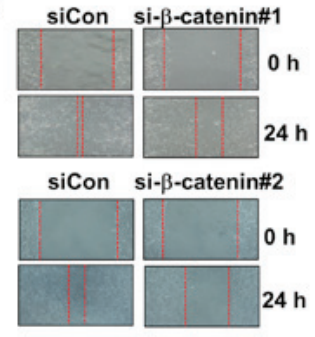

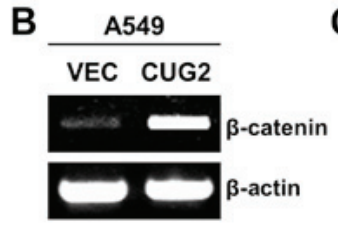
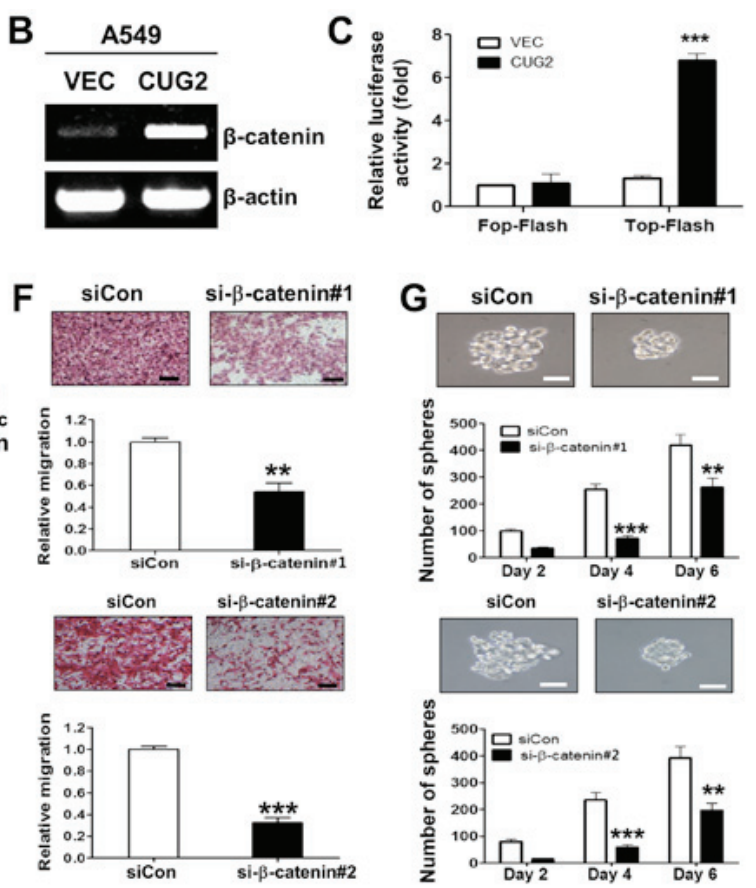

Figure 1. $\beta$-catenin is essential for CUG2-induced CSC-like phenotypes. (A) A549-VEC and A549-CUG2 cells were separated into cytosolic and nuclear fractions. $\beta$-catenin expression was determined by performing western blot analysis with an anti- $\beta$-catenin antibody. Phosphorylation states of $\beta$-catenin following treatment were detected using antibodies against Ser33/Ser37/Thr41, Ser45 and Ser675 of $\beta$-catenin. The cytosolic and nuclear fractions were confirmed by detecting actin and Sp1, respectively. (B) Total RNAs (3 $\mu \mathrm{g})$ were isolated from the A549-VECand A549-CUG2 cells, and cDNAs were synthesized using reverse transcriptase II. $\beta$-catenin gene sequences were amplified using specific primers by using an optimized PCR cycle and were visualized on $1.5 \%$ agarose gels following ethidium bromide staining. $\beta$-actin was used as an internal control. (C) A549-VEC and A549-CUG2 cells were transfected with the Top-Flash $(1 \mu \mathrm{g})$ or Fop-Flash $(1 \mu \mathrm{g})$ luciferase reporter vector and were harvested at $48 \mathrm{~h}$ after the transfection. Transfection efficiency was normalized with that of the $\beta$-galactosidase reporter vector pGK- $\beta$ gal $(1 \mu \mathrm{g})$ during the measurement of luciferase activity. Results are an average of three experiments; bars indicate the means $\pm \mathrm{SD}\left({ }^{* * * *} \mathrm{P}<0.001\right.$, A549-VEC vs A549-CUG2 cells). (D) Transfection of efficiency of $\beta$-catenin siRNAs (\#1 or \#2) was confirmed by western blot analysis. (E) Migration of A549-CUG2 cells was measured with the wound healing assay at $24 \mathrm{~h}$ after control or $\beta$-catenin siRNAs (\#1 and \#2) transfection. Wound closure areas were monitored using a phase-contrast microscope at x100 magnification, and the assay was repeated twice. (F) Invasion of A549-CUG2 cells transfected with control or $\beta$-catenin siRNAs (\#1 and \#2) was determined using the 48-well Boyden chamber. The chamber was assembled using Matrigel-coated polycarbonate filters. Scale bar indicates $100 \mu \mathrm{m}$, and the assay was repeated twice. Each assay was performed in triplicate, and error bars indicate the means $\pm \mathrm{SD}\left({ }^{* * *} \mathrm{P}<0.001\right.$, control vs. $\beta$-catenin siRNA). (G) A549-CUG2 cells (1,000 cells per well) transfected with control or $\beta$-catenin siRNAs (\#1 and \#2) were seeded in ultra-low attachment plates for 2, 4, or 6 days. The assay was performed in triplicate, and error bars indicate the means \pm SD $\left({ }^{* *} \mathrm{P}<0.01\right.$ and ${ }^{* * *} \mathrm{P}<0.001$, control vs. $\beta$-catenin siRNA). Scale bars indicate $50 \mu \mathrm{m}$. CUG2, cancer-upregulated gene 2.

transplantation, the mice were intraperitoneally injected with CGK062 (100 mg/kg body weight), and tumor formation and body weight were monitored for 30 days. As mock treatment, DMSO $(25 \mu \mathrm{l})$ dissolved in PBS (125 $\mu \mathrm{l})$ was used for every injection. The tumor volume was calculated weekly using the following formula: $\mathrm{V}\left(\mathrm{mm}^{3}\right)=0.5 \mathrm{x}$ length $(\mathrm{mm}) \mathrm{x}$ width ${ }^{2}\left(\mathrm{~mm}^{2}\right)$.

TUNEL assay. The mice were euthanized, and their tumor tissues were fixed in $4 \%$ paraformaldehyde in PBS, dehydrated using ethanol and xylene, and embedded in paraffin. Subsequently, the paraffin-embedded tissues were cut into $5-\mu \mathrm{m}$-thick sections, mounted on poly-L-lysine-coated glass slides and analyzed using the ApopAlert DNA fragment kit (Takara, Mountain View, CA, USA), according to the manufacturer's instructions. TUNEL assay involves the catalytic addition of green fluorescein-labeled dUTPs to the 3'-OH end of a DNA fragment by using a terminal deoxynucleotidyl transferase. The resultant green fluorescein-labeled DNA was assessed in 10 random fields using a fluorescence microscope (Zeiss Axio Observer D1, Oberkochen, German).

Statistical analysis. All data are presented as the means \pm standard deviation (SD). Multiple groups were compared by one-way analysis of variance followed by Dunnett's post-hoc test and differences between two groups were analyzed using an unpaired t-test with GraphPad Prism software. A P-value $<0.05$ was considered to indicate a statistically significant difference.

\section{Results}

CUG2 upregulates $\beta$-catenin, which induces CSC-like phenotypes in A549 lung cancer cells. As it was well known that $\mathrm{Wnt} / \beta$-catenin signaling plays an important role in oncogenesis $(7,8)$, we examined whether CUG2 overexpression affects Wnt/ $\beta$-catenin signaling. We found that human A549 lung cancer cells constitutively expressing CUG2 (A549-CUG2) (5) exhibited a higher $\beta$-catenin expression in the cytosolic and nuclear fraction than the A549 cells expressing an empty vector (A549-VEC), although the protein levels of $\beta$-catenin between the A549-CUG2 and A549-VEC cells were indistinguishable in the whole cell lysates due to the abundance of $\beta$-catenin protein (Fig. 1A). The A549-CUG2 cells also had higher levels of $\beta$-catenin gene transcripts than the A549-VEC cells (Fig. 1B). We then introduced a Top-Flash luciferase reporter vector controlled by TCF- 4 protein to examine whether the CUG2-induced increase in $\beta$-catenin levels promotes more interaction 


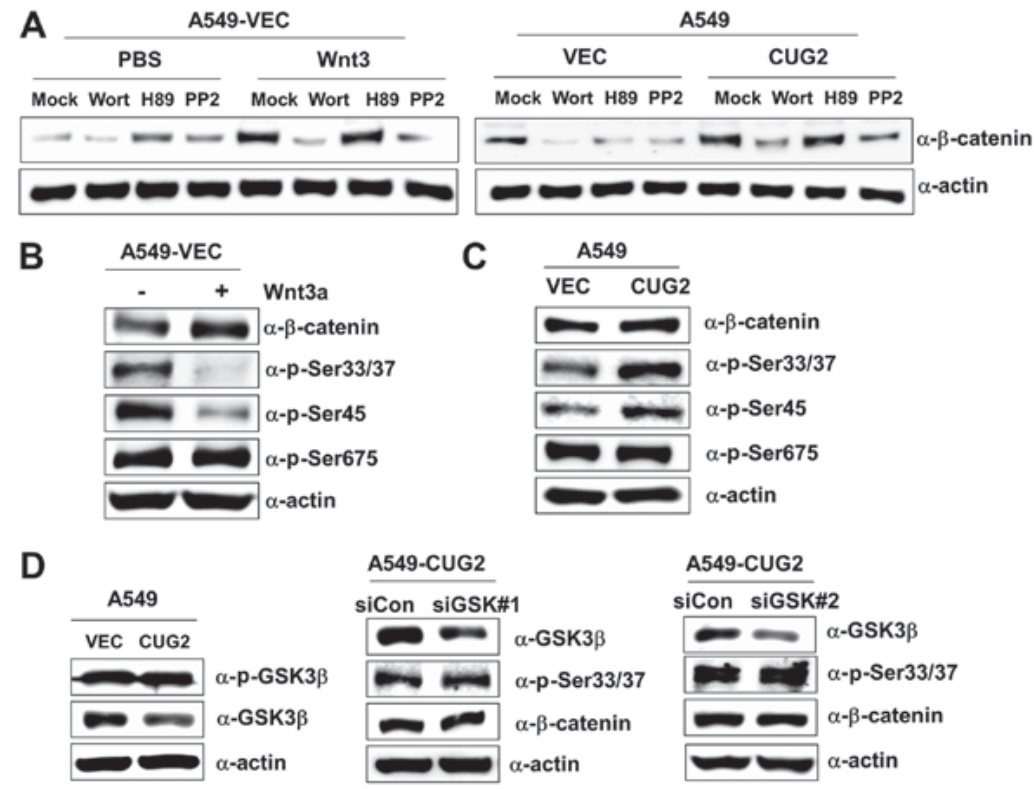

Figure 2. CUG2-induced $\beta$-catenin phosphorylation is unique and differs from that induced by Wnt3a. (A) A549-VEC and A549-CUG2 cells were treated with wortmannin $(10 \mu \mathrm{M}), \mathrm{H} 89(10 \mu \mathrm{M}), \mathrm{PP} 2(2.5 \mu \mathrm{M})$ and DMSO (mock) in the presence of Wnt3a $(100 \mathrm{ng} / \mathrm{ml})$ or PBS as a vehicle for $12 \mathrm{~h}$, and cell lysates were prepared. Proteins present in the cell lysates were separated by performing SDS-PAGE on $10 \%$ gels, and $\beta$-catenin and $\alpha$-actin were detected using corresponding antibodies. (B and C) Proteins present in the lysates of A549-VEC cells treated with Wnt3a (100 ng/ml) or PBS, and of A549-CUG2 cells were separated by performing SDS-PAGE on $10 \%$ gels. Phosphorylation states of $\beta$-catenin following treatment were determined using antibodies against phosphorylated Ser33/Ser37/Thr41, Ser45 and Ser675 of $\beta$-catenin. (D) Lysates of A549-VEC and A549-CUG2 cells treated with a control or GSK3 $\beta$ siRNAs (\#1 and \#2) were separated by performing SDS-PAGE on 10\% gels. GSK3 $\beta$ and phosphorylated GSK3 $\beta$ were detected by performing western blot with corresponding antibodies. CUG2, cancer-upregulated gene 2; GSK3 $\beta$, glycogen synthase kinase $3 \beta$.

between $\beta$-catenin and TCF-binding element in the nucleus. The overexpression of CUG2 enhanced $\beta$-catenin-mediated transcriptional activity, whereas the overexpression of CUG2 and the Fop-Flash vector carrying a mutant TCF-binding site did not enhance $\beta$-catenin-mediated transcriptional activity (Fig. 1C). Collectively, these results suggest that CUG2 overexpression induces the transcriptional activity of $\beta$-catenin, increases the level of $\beta$-catenin and activates its downstream targets.

We then examined whether upregulated $\beta$-catenin is closely associated with CUG2-induced CSC-like phenotypes. For this purpose, we examined whether the suppression of $\beta$-catenin expression impedes CUG2-induced EMT and sphere formation, which are the features of CSC phenotypes. We found that $\beta$-catenin gene knockdown using a specific siRNA (\#1 or \#2; Fig. 1D) reduced the wound healing and invasive ability of the A549-CUG2 cells compared with that of the cells transfected with a control siRNA (Fig. 1E and F). This result indicates that upregulated $\beta$-catenin expression is involved in CUG2-induced EMT. Furthermore, $\beta$-catenin silencing using specific siRNAs (\#1 or \#2) decreased the number and size of A549-CUG2 cell spheroids compared with that of the cells transfected with the control siRNA (Fig. 1G). Thus, these results suggest that $\beta$-catenin plays a crucial role in promoting CUG2-induced CSC-like phenotypes.

The CUG2-induced phosphorylation of $\beta$-catenin differs from that induced by Wnt3a. We then wished to determine whether the CUG2-mediated upregulation of $\beta$-catenin expression emulates activation patterns induced via the Wnt3a signaling pathway. The Akt, PKA and Src signaling proteins directly or indirectly regulate $\mathrm{Wnt} / \beta$-catenin signaling; thus, we examined their effects on $\beta$-catenin expression in the presence of CUG2 overexpression. The A549-VEC cells were treated with wortmannin (an Akt inhibitor), H89 (a PKA inhibitor), or PP2 (a Src inhibitor) in the presence of Wnt3a. Wortmannin and PP2 treatments inhibited $\beta$-catenin expression in the A549-VEC cells, although H89 treatment did not (Fig. 2A). Similarly, wortmannin and PP2 treatments decreased $\beta$-catenin expression in the presence of CUG2 overexpression, although H89 treatment did not (Fig. 2A). These results suggest the presence of shared pathways between Wnt3a- and CUG2-mediated signaling in regulating $\beta$-catenin. To delineate the two signaling pathways, we examined the phosphorylation pattern of $\beta$-catenin. Wnt3a treatment decreased the phosphorylation of $\beta$-catenin at Ser33/Ser37 and Ser45 compared with mock treatment, although it did not affect its phosphorylation at Ser675 (Fig. 2B). By contrast, CUG2 overexpression increased the phosphorylation of $\beta$-catenin at Ser33/Ser37 and Ser45, although it did not affect its phosphorylation at Ser675, similar to Wnt3a treatment (Fig. 2C). This result indicates the distinct regulation of $\beta$-catenin by the Wnt3a- and CUG2-mediated signaling pathways. As GSK3 $\beta$ phosphorylates $\beta$-catenin at Ser33/Ser37 to promote its degradation (17-19), we examined the role of GSK3 $\beta$ in the phosphorylation of $\beta$-catenin at Ser33/Ser37 in the A549-CUG2 cells. We found that the A549-CUG2 cells exhibited a decreased GSK3 $\beta$ expression compared with the A549-VEC cells, but similar phosphorylated GSK3 $\beta$ levels (Fig. 2D). Moreover, the suppression of GSK3 $\beta$ expression using a specific siRNA (\#1 or \#2) did not affect the levels of $\beta$-catenin and phosphorylation at Ser33/Ser37 in the A549-CUG2 cells (Fig. 2D), indicating that CUG2-induced $\beta$-catenin phosphorylation is independent of GSK3 $\beta$. 
A
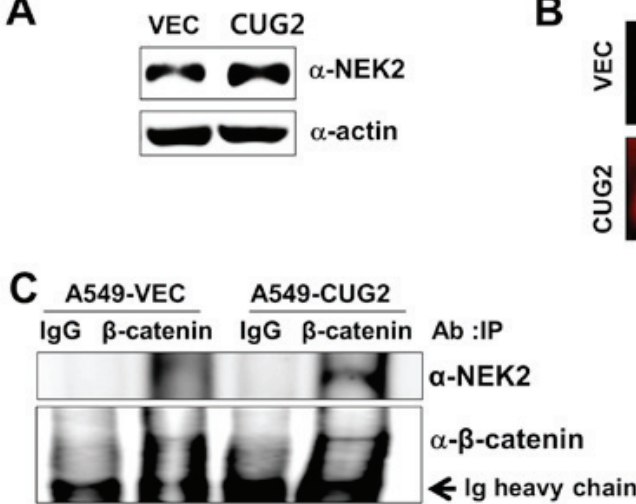

E

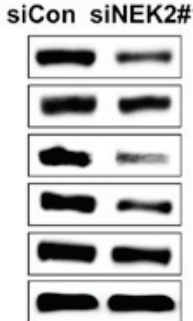

Ig heavy chain

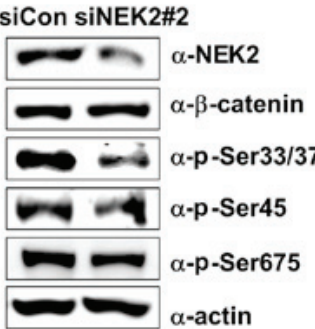

B

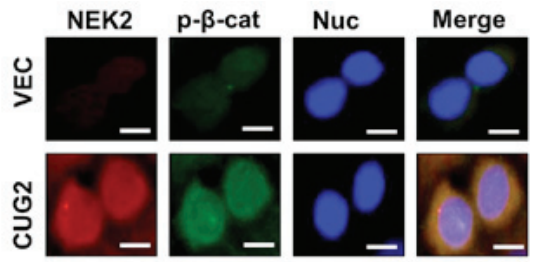

D A549-VEC A549-CUG2
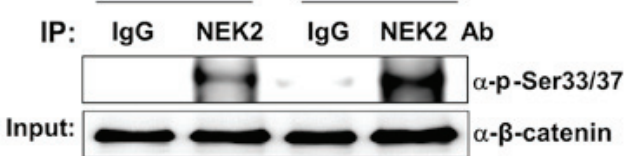

$\mathbf{F}$

A549-CUG2

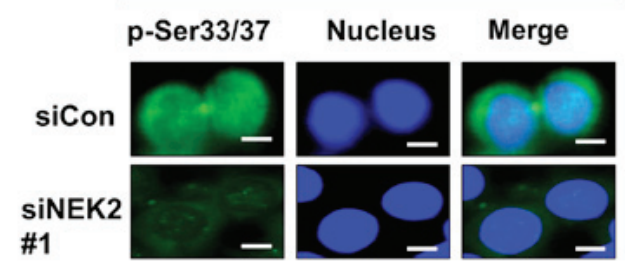

Figure 3. CUG2-activated NEK2 is responsible for the phosphorylation of $\beta$-catenin at Ser33/Ser37. (A) Lysates of A549-VEC and A549-CUG2 cells were separated by performing SDS-PAGE on $10 \%$ gels, and NEK2 was detected by performing western blot analysis with anti-NEK2 antibody. (B) Levels of NEK2 and $\beta$-catenin phosphorylated at Ser33/Ser37 (p- $\beta$-catenin; p-Ser33/Ser37) in A549-VEC and A549-CUG2 cells were determined by performing immunofluorescence microscopy with Alexa Fluor 594-conjugated goat anti-mouse IgG (red) and Alexa Fluor 488-conjugated goat anti-rabbit IgG (green), respectively. For performing nuclear staining, DAPI was added before mounting in glycerol. Scale bar indicates $10 \mu \mathrm{m}$. (C) $\beta$-catenin was pulled down from the lysates of A549-VEC and A549-CUG2 cells by using an anti- $\beta$-catenin antibody. NEK2 present in the immunoprecipitates was detected using an anti-NEK2 antibody, and $\beta$-catenin present in the immunoprecipitates was detected as a loading control by using an anti- $\beta$-catenin antibody. (D) NEK2 was pulled down from A549-VEC and A549-CUG2 cells by using an anti-NEK2 antibody or isotype IgG as a control. The reaction mixture for the NEK2 kinase assay, including immunoprecipitates as NEK2 kinase, recombinant GST- $\beta$-catenin as a substrate, ATP, and a reaction buffer, was incubated at $30^{\circ} \mathrm{C}$ for $1 \mathrm{~h}$. NEK 2 kinase activity was analyzed by determining the phosphorylation of GST- $\beta$-catenin at Ser33/Ser37 by performing immunoblotting, and $\beta$-catenin levels were examined as a loading control. (E) Lysates of A549-CUG2 cells transfected with the control or NEK2 siRNAs (\#1 and \#2) were separated by performing SDS-PAGE on $10 \%$ gels. Phosphorylation states of $\beta$-catenin following treatment were detected using antibodies against Ser33/Ser37/Thr41, Ser45 and Ser675 of $\beta$-catenin. (F) Following transfection with control or NEK2 siRNA\#1, the levels of p- $\beta$-catenin (p-Ser33/Ser37) in A549-CUG2 cells were detected by performing immunofluorescence microscopy with Alexa Fluor 488-conjugated goat anti-rabbit IgG (green). For performing nuclear staining, DAPI was added before mounting in glycerol. Scale bar indicates $10 \mu \mathrm{m}$. CUG2, cancer-upregulated gene 2; NEK2, never in mitosis gene A-related kinase 2.

CUG2-mediated NEK2 activation is involved in the phosphorylation of $\beta$-catenin at Ser33/Ser37. Subsequently, when we explored the mechanism underlying the phosphorylation of $\beta$-catenin at Ser33/Ser37 in the presence of CUG2 overexpression. A previous study reported that NEK 2 phosphorylates $\beta$-catenin at the same regulatory sites (Ser33/Ser37) and binds to $\beta$-catenin (30). By preventing E3 ligase $\beta$-TrCP from accessing $\beta$-catenin, NEK2 contributes to the stabilization of $\beta$-catenin (30). Thus, in this study, we measured the NEK2 expression levels in the A549-VEC and A549-CUG2 cells. The A549-CUG2 cells exhibited higher NEK2 levels than the A549-VEC cells (Fig. 3A). To explore the association between NEK2 and $\beta$-catenin, we examined the localization of NEK 2 and $\beta$-catenin phosphorylated at Ser33/Ser37 ( $p-\beta$-catenin), as well as the interaction between NEK 2 and $\beta$-catenin. Although $p-\beta$-catenin was detected in both the cytoplasm and nucleus, $p-\beta$-catenin was preferentially detected in the nucleus (Fig. 1A). This result was confirmed by performing immunofluorescence microscopy with Alexa 488-conjugated anti-p- $\beta$-catenin antibody (Fig. 3B). We also found that NEK2 exhibited greater localization to the nucleus than to the cytoplasm, essentially overlapping with the localization of $p-\beta$-catenin (Fig. 3B). Abundant NEK2 levels were detected in the immunocomplexes of A549-CUG2 cells pulled down by using anti- $\beta$-catenin antibody, supporting the co-localization of NEK 2 and $\beta$-catenin (Fig. 3C). The immunocomplexes that were pulled down by anti-NEK2 antibody from the lysates of the A549-VEC or A549-CUG2 cells were incubated with purified GST- $\beta$-catenin and ATP. The lysates of the A549-CUG2 cells exhibited a greater NEK2 kinase activity than those of the A549-VEC cells (Fig. 3D). To confirm the role of NEK2 in the phosphorylation of $\beta$-catenin at Ser33/Ser37, we examined whether NEK2 silencing indeed decreases the phosphorylation of $\beta$-catenin at Ser33/Ser37. We found that NEK2 silencing using a specific siRNA (\#1 or \#2) evidently reduced the phosphorylation of $\beta$-catenin at Ser33/Ser37 and Ser45, but very slightly at Ser675 (Fig. 3E and 3F). NEK2 slightly decreased the level of total $\beta$-catenin (Fig. 3E). Taken together, these results indicate that CUG2 overexpression increases the expression and kinase activity of NEK2 responsible for the phosphorylation of $\beta$-catenin at Ser33/Ser37.

CGK062 treatment promotes the degradation of $\beta$-catenin through PKC $\alpha$ in the presence of CUG2 overexpression. Our previous study reported that the small chemical molecule CGK062 activates PKC $\alpha$, leading to the phosphorylation of $\beta$-catenin at Ser33/Ser37 for its rapid degradation (23). 
A

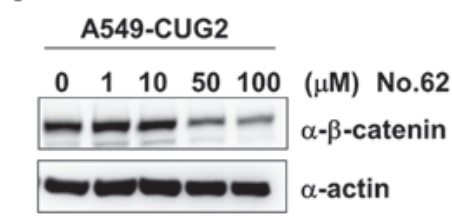

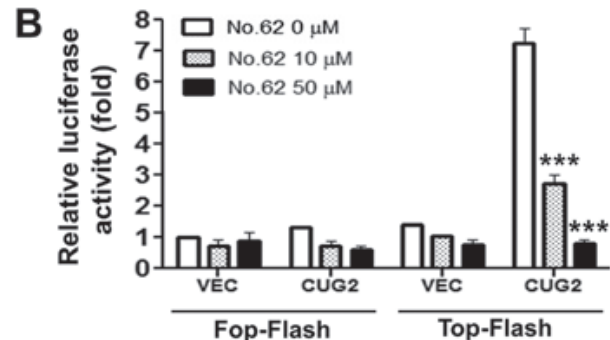

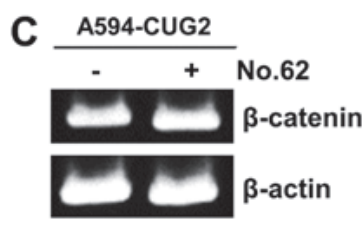

E
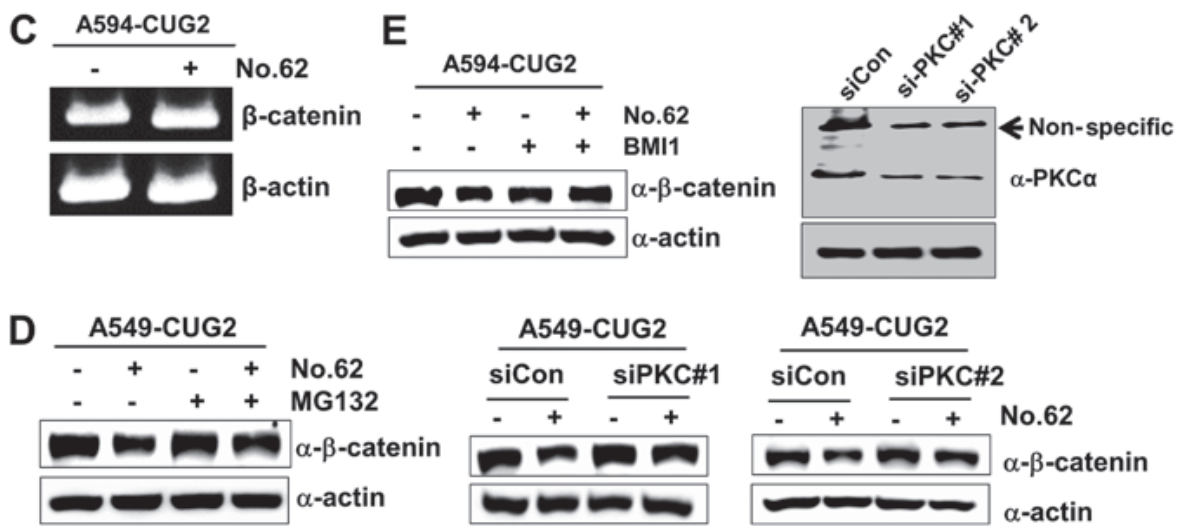

Figure 4. CGK062 treatment destabilizes $\beta$-catenin in a proteasome- and PKC $\alpha$ - dependent manner. (A) A549-CUG2 cells were treated with CGK062 (0, 1 , 10,50 and $100 \mu \mathrm{M}$ ) for $24 \mathrm{~h}$, and $\beta$-catenin levels were measured by performing western blot analysis with an anti- $\beta$-catenin antibody. (B) A549-CUG2 cells were transfected with the Top-Flash $(1 \mu \mathrm{g})$ or Fop-Flash $(1 \mu \mathrm{g})$ luciferase reporter vector in the presence of CGK062 $(50 \mu \mathrm{M})$ and were harvested at $48 \mathrm{~h}$ following transfection. Transfection efficiency was normalized with that of the $\beta$-galactosidase reporter vector pGK- $\beta$ gal $(1 \mu \mathrm{g})$ during the measurement of luciferase activity. Results shown are an average of 3 experiments; bars indicate the means $\pm \mathrm{SD}\left({ }^{* * *} \mathrm{P}<0.001,0 \mathrm{vs}\right.$. $10 \mu \mathrm{M}, 0 \mathrm{vs}$. $\left.50 \mu \mathrm{M}\right)$. (C) Total RNAs $(3 \mu \mathrm{g})$ were isolated from A549-CUG2 cells treated with or without CGK062 (50 $\mu \mathrm{M})$, and cDNAs were synthesized using reverse transcriptase II. $\beta$-catenin gene sequences were amplified using specific primers by using an optimized PCR cycle and were visualized on $1.5 \%$ agarose gels following ethidium bromide staining. $\beta$-actin was used as an internal control. (D) A549-CUG2 cells were treated with MG132 ( $1 \mu \mathrm{M})$ for $8 \mathrm{~h}$ in the absence or presence of CGK062 (50 $\mu \mathrm{M})$ and were harvested. $\beta$-catenin levels were measured by performing western blot analysis with an anti- $\beta$-catenin antibody. (E) A549-CUG2 cells were treated with BMI $(7.5 \mu \mathrm{M})$, a specific PKC $\alpha$ inhibitor, or were transfected with a control and PKC $\alpha$ siRNAs (\#1 or \#2) in the absence or presence of CGK062 (50 $\mu \mathrm{M})$ for $24 \mathrm{~h}$. Transfection efficiency of PKC $\alpha$ siRNAs (\#1 or \#2) was confirmed by western blot analysis. $\beta$-catenin levels were measured by performing western blot analysis with an anti- $\beta$-catenin antibody. CUG2, cancer-upregulated gene 2 ; PKC, protein kinase C.

Therefore, in this study, we examined whether CGK062 induces $\beta$-catenin degradation in the presence of CUG2 overexpression. We found that CGK062 treatment reduced the protein levels of $\beta$-catenin and $\beta$-catenin-mediated promoter activity in a dose-dependent manner (Fig. 4A and B). To determine whether CGK062 treatment affects the mRNA levels of $\beta$-catenin, we performed RT-PCR. We found that CGK062 did not decrease the mRNA levels of $\beta$-catenin (Fig. 4C). To examine whether the CGK062-induced $\beta$-catenin degradation is dependent on a proteasome-mediated pathway, we treated the cells with MG132, a proteasome inhibitor, in the presence of CGK062. CGK062 treatment alone reduced the $\beta$-catenin levels; however, MG132 treatment prevented the CGK062-mediated $\beta$-catenin degradation, suggesting that the CGK062-induced $\beta$-catenin degradation is dependent on a proteasome-mediated pathway (Fig. 4D). To confirm that $\mathrm{PKC} \alpha$ is involved in CGK062-induced $\beta$-catenin degradation, the A549-CUG2 cells were treated with BMI, a PKC inhibitor, or PKC $\alpha$ siRNA in the presence of CGK062. Treatment with both BMI and PKC $\alpha$ siRNA (\#1 or \#2) inhibited the CGK062-induced $\beta$-catenin degradation (Fig. 4E), indicating that CGK062 treatment suppresses the CUG2-induced enhancement of $\beta$-catenin expression.

CGK062 treatment inhibits NEK2 expression and kinase activity in A549-CUG2 cells. As CGK062 treatment decreased the $\beta$-catenin levels, we wished to examine whether it also affects NEK2 expression in the presence of CUG2 overexpression. Surprisingly, we found that CGK062 treatment, but not DMSO treatment, reduced NEK2 expression in a dose-dependent manner in the A549-CUG2 cells (Fig. 5A). The results of immunofluorescence microscopy also revealed that CGK062 treatment reduced the p- $\beta$-catenin and NEK2 staining levels, supporting the results of western blot analysis (Fig. 5B). Moreover, CGK062 treatment decreased NEK2 kinase activity in vitro (Fig. $5 \mathrm{C}$ ). Although the mechanisms underlying the effects of CGK062 on NEK2 are unknown, our results indicate that CGK062 affects both $\beta$-catenin and NEK2.

CGK062 treatment inhibits CUG2-induced CSC-like phenotypes. In light of our above-mentioned finding that $\beta$-catenin is involved in CUG2-induced CSC-like phenotypes (Fig. 1), we examined the hypothesis that CGK062 treatment impedes the formation of CUG2-induced CSC-like phenotypes. For this purpose, we evaluated the recovery and invasion of A549-CUG2 cells after wound induction and found that CGK062 treatment reduced cell recovery after wound induction and invasion into the lower wells (Fig. 6A and B). To determine the CGK062-induced inhibition of these EMT phenomena, we examined the biochemical features of EMT, such as the E-cadherin, N-cadherin and vimentin 


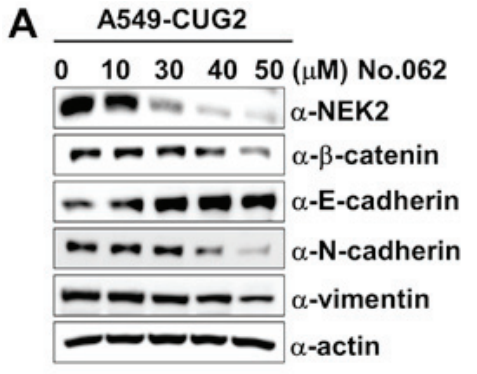

B
C

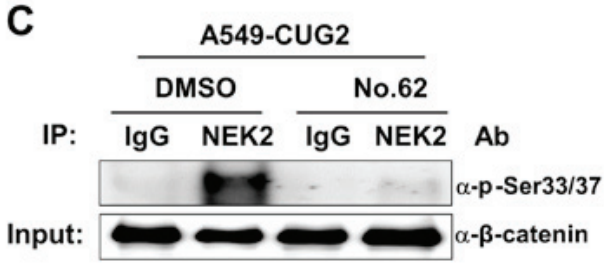

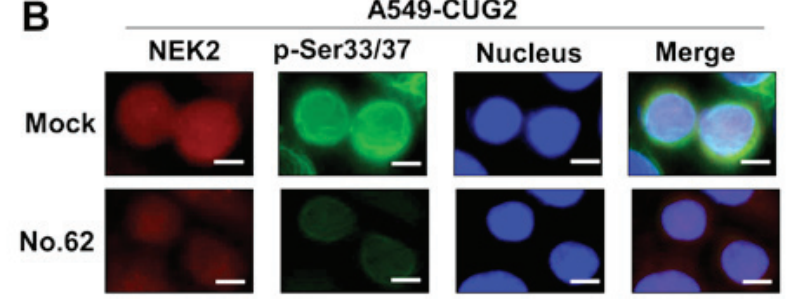

Figure 5. CGK062 treatment decreases NEK2 expression and kinase activity in A549-CUG2 cells. (A) Lysates of A549-CUG2 cells treated with CGK062 $(0,10,30,40$ and $50 \mu \mathrm{M})$ for $24 \mathrm{~h}$ were separated by performing SDS-PAGE on $10 \%$ gels. The expression of NEK2, $\beta$-catenin, E-cadherin, N-cadherin and vimentin was detected by performing western blot analysis with corresponding antibodies. (B) Levels of NEK2 and p- $\beta$-catenin (p-Ser33/Ser37) in A549-CUG2 cells treated with CGK062 $(50 \mu \mathrm{M})$ or DMSO as Mock were detected by performing immunofluorescence microscopy with Alexa Fluor 594-conjugated goat anti-mouse IgG (red) and Alexa Fluor 488-conjugated goat anti-rabbit IgG (green), respectively. For performing nuclear staining, DAPI was added before mounting in glycerol. Scale bar indicates $10 \mu \mathrm{m}$. (C) NEK2 was pulled down from A549-VEC and A549-CUG2 cells treated with CGK062 (50 $\mu \mathrm{M})$ or DMSO by using the anti-NEK2 antibody or isotype IgG as a control. The reaction mixture for the NEK2 kinase assay was incubated at $30^{\circ} \mathrm{C}$ for $1 \mathrm{~h}$. NEK2 kinase activity was analyzed by detecting the phosphorylation of GST- $\beta$-catenin at Ser33/Ser37 by performing western blot analysis, and $\beta$-catenin levels were examined as a loading control. CUG2, cancer-upregulated gene 2; NEK2, never in mitosis gene A-related kinase 2.
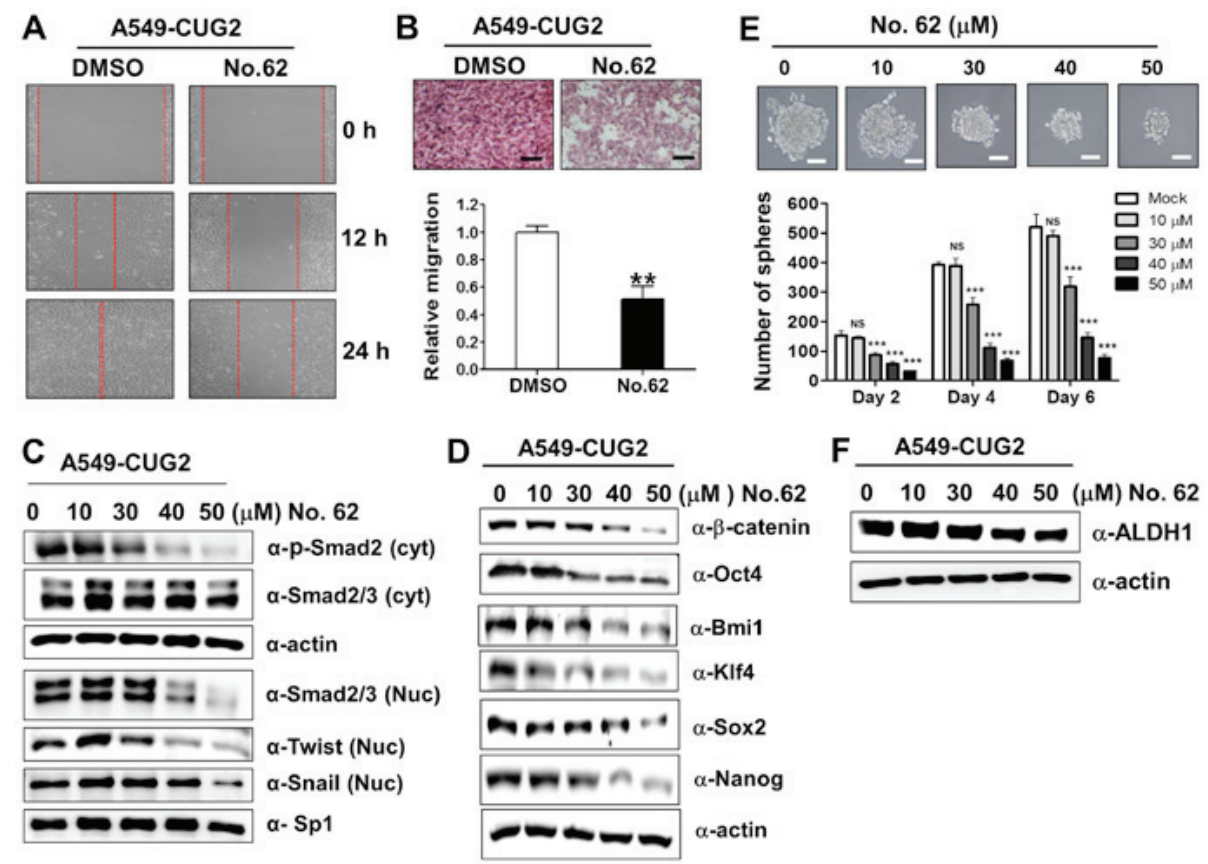

Figure 6. CGK062 treatment inhibits CUG2-induced CSC-like phenotypes. (A) Migration of A549-CUG2 cells treated with CGK062 (50 $\mu$ M) or DMSO (control) was measured by performing wound healing assay. Wound closure areas were monitored using a phase-contrast microscope at x 100 magnification, and the assay was repeated twice. (B) Invasion of A549-CUG2 cells treated with CGK062 (50 $\mu \mathrm{M})$ or DMSO was determined using the 48-well Boyden chamber. The chamber was assembled using Matrigel-coated polycarbonate filters. Scale bar indicates $100 \mu \mathrm{m}$, and the assay was repeated twice. Each assay was performed in triplicate, and error bars indicate the means $\pm \mathrm{SD}\left({ }^{* *} \mathrm{P}<0.01\right.$, DMSO vs. CGK062). (C, D and F) Lysates of A549-CUG2 cells treated with CGK062 (0, 10, 30,40 and $50 \mu \mathrm{M}$ ) or DMSO were separated by performing SDS-PAGE on 10\% gels, and expression of phosphorylated Smad2, Smad2/3, Twist, Snail, Oct4, Bmi1, Klf4, Sox2, Nanog and ALDH1 was determined by performing western blot analysis with corresponding antibodies. (E) A549-CUG2 cells treated with CGK062 $(0,10,30,40$ and $50 \mu \mathrm{M})$ or DMSO (1,000 cells per well) were seeded in ultra-low attachment plates for 2, 4 or 6 days. The assay was performed in triplicate, and error bars indicate the means $\pm \mathrm{SD}$ (ns; not significant, DMSO vs. CGK062 at $10 \mu \mathrm{M},{ }^{* * * *} \mathrm{P}<0.001$, DMSO vs. CGK062 at 30,40 and $50 \mu \mathrm{M}$ ). Scale bars indicate $50 \mu \mathrm{m}$. CUG2, cancer-upregulated gene 2 .

levels, in the A549-CUG2 cells treated with CGK062. As expected, CGK062 treatment decreased the $\mathrm{N}$-cadherin and vimentin levels, but increased the E-cadherin levels, which is opposite of that observed during EMT induction (Fig. 5A). 

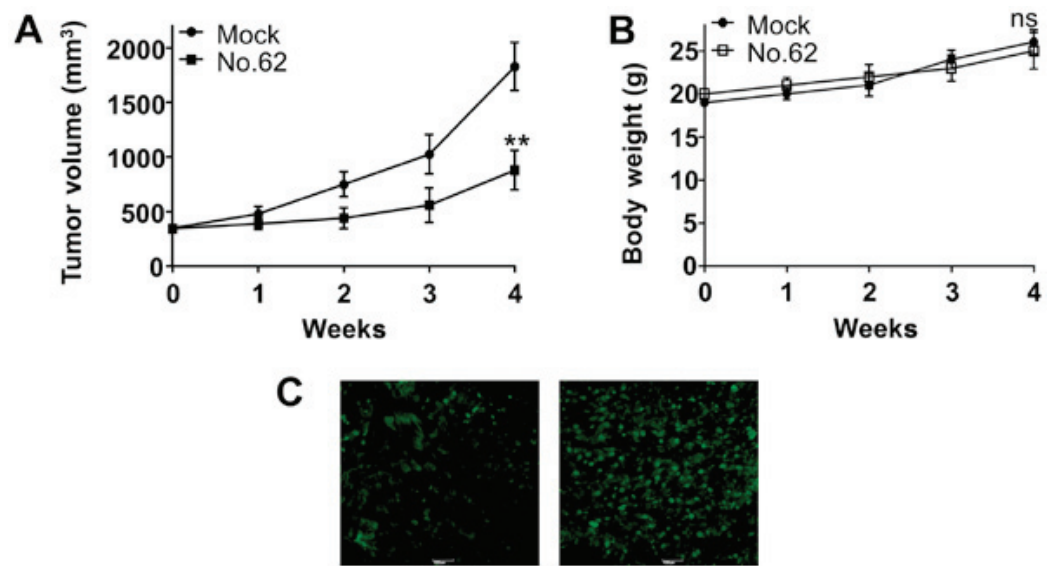

Mock

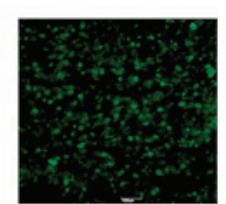

No. 62

Figure 7. CGK062 treatment inhibits CUG2-induced tumor development in vivo. (A and B) Balb/C nude mice were subcutaneously transplanted with A549-CUG2 cells ( $1 \times 10^{6}$ cells/mouse) for 2 weeks and were intraperitoneally injected with CGK062 (100 mg/kg body weight) for 4 weeks. Tumor sizes and body weights were measured for 4 weeks [ ${ }^{* *} \mathrm{P}<0.01$, mock $(\mathrm{n}=6)$ vs. CGK062 $(\mathrm{n}=6)$; ns; not significant]. (C) At 4 weeks after the treatment, tumor tissues harvested from the mice were embedded in paraffin and were sectioned for performing the TUNEL assay. Green fluorescence indicates apoptotic cells.

Moreover, as TGF- $\beta$ signaling is closely involved in EMT and Wnt/ $\beta$-catenin signaling (31), we examined whether CGK062 treatment impairs TGF- $\beta$ signaling. We found that CGK062 treatment decreased phosphorylated the Smad2, Snail and Twist levels (Fig. 6C), indicating the existence of a crosstalk between TGF- $\beta$ and $\beta$-catenin signaling.

Furthermore, as we hypothesized that CGK062 treatment enabled to interrupt CUG2-induced stemness on the basis of results from Figs. 1 and 4, we measured the expression levels of transcription factors or co-factors associated with stemness and the number and size of A549-CUG2 cell spheroids following CGK062 treatment. We found that CGK062 treatment decreased the Bmi1, Klf4, Oct4, Sox2 and Nanog levels (Fig. 6D). The effect of CGK062 was clearly detected from $30 \mu \mathrm{M}$. Moreover, CGK062 treatment significantly decreased the number and size of A549-CUG2 cell spheroids compared with mock treatment (Fig. 6E). We then examined the expression of aldehyde dehydrogenase 1 (ALDH1), a biochemical feature of stemness, and found that CGK062 treatment decreased the level of this protein (Fig. 6F). Taken together, these results suggest that CGK062 treatment inhibits CSC-like phenotypes in A549-CUG2 cells.

CGK062 treatment impairs CUG2-mediated tumor formation in transplanted nude mice. Finally, we examined whether CGK062 treatment inhibits CUG2-induced tumor formation in vivo. For this, Balb/C nude mice were subcutaneously transplanted with A549-CUG2 cells into their right flanks and were intraperitoneally injected with CGK062 for 30 days. We found that CGK062 treatment significantly decreased CUG2-induced tumor formation in Balb/C nude mice, although mock treatment did not (Fig. 7A). Moreover, no significant change in body weights was observed in the mockor CGK062-treated mice during the treatment period (Fig. 7B). We then performed TUNEL assay to determine the presence of apoptotic cells in tumor tissues isolated from mock- or CGK062-treated mice and found higher numbers of stained cells in the tumor tissues isolated from CGK062-treated mice than in those isolated from mock-treated mice (Fig. 7C). These results indicate that CGK062 exerts a cytotoxic effect on tumorigenic A549-CUG2 lung cancer cells in vivo.

\section{Discussion}

In the present study, we found that CUG2 specifically activated and stabilized $\beta$-catenin to induce the features of malignant cancer, including increased cell migration, aggressive invasion, enforced sphere formation and tumor formation in vivo. Moreover, we found that the CUG2-induced phosphorylation of $\beta$-catenin followed a different pattern compared with that induced by Wnt3a. Surprisingly, despite the involvement of the Akt and Src signaling molecules in both CUG2- and Wnt3a-mediated signaling pathways, CUG2 stabilized $\beta$-catenin by inducing its hyperphosphorylation at Ser33/Ser37, which is traditionally suggested to induce the ubiquitination and proteasomal degradation of $\beta$-catenin. As expected, Wnt3a did not phosphorylate $\beta$-catenin at Ser33/Ser37 in the presence of CUG2 overexpression. These results suggest that CUG2 recruits or activates a signaling molecule to prevent the predicted ubiquitin E3 ligase-mediated degradation of $\beta$-catenin. Growing evidence indicates that a long form of FLICE/caspase 8 inhibitory protein (cFLIP) stabilizes $\beta$-catenin (32). Furthermore, another study reported that acetyltransferase $\mathrm{p} 300 / \mathrm{CBP}$-associated factor (PCAF) directly acetylated and stabilized $\beta$-catenin and that protease-activated receptor-1 (PAR-1) stabilized $\beta$-catenin through Ga13 independently of Wnt signaling (33). Herein, we focused on NEK2 as it physically interacts with and phosphorylates $\beta$-catenin at Ser33/Ser27 (30). We found that CUG2 enhanced NEK2 expression. NEK2 silencing reduced the phosphorylation of $\beta$-catenin at Ser33/Ser37, but did not decrease the level of total $\beta$-catenin. As the interaction of NEK 2 with $\beta$-catenin interrupts the binding of GSK3 $\beta$ to $\beta$-catenin (30), we expected that $N E K 2$ knockdown facilitated the binding of GSK3 $\beta$ to $\beta$-catenin, leading to its phosphorylation at Ser33/Ser37 and subsequent degradation through the E3 ligase $\beta$-TrCP. However, we did not observe any change in the $\beta$-catenin levels. Moreover, GSK $3 \beta$ inhibition 
or silencing did not increase the $\beta$-catenin levels. In our next study, we aim to examine whether the long form of cFLIP, PCAF, or PAR-1 participates in $\beta$-catenin stabilization in the presence of CUG2 overexpression. Furthermore, we aim to determine the mechanisms underlying the CUG2-induced increase in NEK2 expression in our future studies.

During interphase, centrosomes are held together by a proteinaceous linker. At the onset of mitosis, this linker is dissembled to facilitate centrosome separation and bipolar spindle formation (34). NEK2 is implicated to be involved in this process, which is known as centrosome disjunction (34). Besides its cellular effects, NEK2 overexpression activates Ras-Src, PI3 kinase, and Wnt signaling pathways to promote metastasis (35). Consistently, aberrant NEK2 expression has been reported in various cancers, including hepatocellular carcinoma (36), non-small cell lung (37), colon (38), brain (39), and ovarian cancers (40). Based on these lines of clinical evidence, small-molecule drugs have been designed or screened for targeting the potentially oncogenic NEK2 (41-43).

Notably, treatment with CGK062, which destabilizes $\beta$-catenin through PKC $\alpha$, reduced the NEK2 levels. Although the molecular mechanisms underlying this finding are unclear, this result suggests that NEK2 expression is affected by the $\beta$-catenin levels. Thus, our next assignment will aim to illustrate how CGK062 decreases the protein levels of NEK2. A recent study synthesized (+)-decursin derivatives substituted with cinnamoyl- and phenyl propiony groups using (+)-CGK062 as a leading compound (44). The decursin derivatives inhibited Wnt3a-induced $\beta$-catenin response transcription and enhanced degradation of $\beta$-catenin, leading to the suppression of cyclin D1 and c-Myc expression (44). Other synthetic decursin derivatives also exhibited suppression of androgen receptor signaling (45).

In conclusion, the findings of this study demonstrated that CUG2 overexpression increased the phosphorylation of $\beta$-catenin at Ser33/Ser37 through the elevated NEK2 expression and activity. This event provided the resistance of $\beta$-catenin to E3 ligase for degradation. Consequently, the upregulated $\beta$-catenin was involved in CUG2-induced CSC-like phenotypes. However, treatment with CGK062 reduced the protein levels of $\beta$-catenin through NEK2. We thus suggest that CGK062 may be used as a potential drug against CUG2-overexpressing lung cancer cells.

\section{Acknowledgements}

The authors would like to thank Dr Charles C. Chung (Rochester General Hospital, Rochester, NY, USA) for proofreading this manuscript.

\section{Funding}

This study was supported by the Basic Research Program of the National Research Foundation funded by the Korean government (NRF-2016R 1D1A1B03930168). This study was also supported by Korea Institute for Advancement of Technology (KIAT) in Republic of Korea (N0002310, Construction Project of Supporting Center for Commercializing Customized Nano-mold-based Technologies).

\section{Availability of data and materials}

The datasets used and/or analyzed during the current study are available from the corresponding author on reasonable request.

\section{Authors' contributions}

SK, SO, SSK and YHC conceived and designed the experiments. SK, JM, AYY, MRL, JEK, DYH and SEY performed the experiments. HYK and SSK were involved in data analysis and compilation. SK and YHC wrote the manuscript. All authors have read and approved the manuscript and agree to be accountable for all aspects of the research in ensuring that the accuracy or integrity of any part of the work are appropriately investigated and resolved.

\section{Ethics approval and consent to participate}

All animal experiments were conducted in accordance with the Laboratory Animal Resources Guide for the Care and Use of Laboratory Animals. All animal study protocols were approved by the Pusan National University Animal Care and Use Committee (PNU-2017-1541).

\section{Patient consent for publication}

Not applicable.

\section{Competing interests}

The authors declare that they no competing interests.

\section{References}

1. Lee S, Gang J, Jeon SB, Choo SH, Lee B, Kim YG, Lee YS, Jung J, Song SY and Koh SS: Molecular cloning and functional analysis of a novel oncogene, cancer-upregulated gene 2 (CUG2). Biochem Biophys Res Commun 360: 633-639, 2007.

2. Hori T, Amano M, Suzuki A, Backer CB, Welburn JP, Dong Y, McEwen BF, Shang WH, Suzuki E, Okawa K, et al: CCAN makes multiple contacts with centromeric DNA to provide distinct pathways to the outer kinetochore. Cell 135: 1039-1052, 2008.

3. Kim H, Lee M, Lee S, Park B, Koh W, Lee DJ, Lim DS and Lee S: Cancer-upregulated gene 2 (CUG2), a new component of centromere complex, is required for kinetochore function. Mol Cells 27: 697-701, 2009.

4. Park EH, Park EH, Cho IR, Srisuttee R, Min HJ, Oh MJ, Jeong YJ, Jhun BH, Johnston RN, Lee S, et al: CUG2, a novel oncogene confers reoviral replication through Ras and p38 signaling pathway. Cancer Gene Ther 17: 307-314, 2010.

5. Kaowinn S, Kim J, Lee J, Shin DH, Kang CD, Kim DK, Lee S, Kang MK, Koh SS, Kim SJ, et al: Cancer upregulated gene 2 induces epithelial-mesenchymal transition of human lung cancer cells via TGF- $\beta$ signaling. Oncotarget 8: 5092-5110, 2017.

6. Kaowinn S, Jun SW, Kim CS, Shin DM, Hwang YH, Kim K, Shin B, Kaewpiboon C, Jeong HH, Koh SS, et al: Increased EGFR expression induced by a novel oncogene, CUG2, confers resistance to doxorubicin through Stat1-HDAC4 signaling. Cell Oncol (Dordr) 40: 549-561, 2017.

7. Peifer M and Polakis P: Wnt signaling in oncogenesis and embryogenesis - a look outside the nucleus. Science 287 : 1606-1609, 2000.

8. Huelsken $\mathrm{J}$ and Birchmeier W: New aspects of Wnt signaling pathways in higher vertebrates. Curr Opin Genet Dev 11: 547-553, 2001.

9. Giles RH, van Es JH and Clevers H: Caught up in a Wnt storm: Wnt signaling in cancer. Biochim Biophys Acta 1653: 1-24, 2003.

10. Tetsu O and McCormick F: Beta-catenin regulates expression of cyclin D1 in colon carcinoma cells. Nature 398: 422-426, 1999. 
11. He TC, Sparks AB, Rago C, Hermeking H, Zawel L, da Costa LT, Morin PJ, Vogelstein B and Kinzler KW: Identification of c-MYC as a target of the APC pathway. Science 281: 1509-1512, 1998.

12. He TC, Chan TA, Vogelstein B and Kinzler KW: PPARdelta is an APC-regulated target of nonsteroidal anti-inflammatory drugs. Cell 99: 335-345, 1999.

13. Saadeddin A, Babaei-Jadidi R, Spencer-Dene B and Nateri AS: The links between transcription, beta-catenin/JNK signaling, and carcinogenesis. Mol Cancer Res 7: 1189-1196, 2009.

14. Damsky WE, Curley DP, Santhanakrishnan M, Rosenbaum LE, Platt JT, Gould Rothberg BE, Taketo MM, Dankort D, Rimm DL, McMahon $\mathrm{M}$, et al: $\beta$-catenin signaling controls metastasis in Braf-activated Pten-deficient melanomas. Cancer Cell 20: 741-754, 2011.

15. Liu L, Zhu XD, Wang WQ, Shen Y, Qin Y, Ren ZG, Sun HC and Tang ZY: Activation of beta-catenin by hypoxia in hepatocellular carcinoma contributes to enhanced metastatic potential and poor prognosis. Clin Cancer Res 16: 2740-2750, 2010.

16. Yook JI, Li XY, Ota I, Hu C, Kim HS, Kim NH, Cha SY, Ryu JK, Choi YJ, Kim J, et al: A Wnt-Axin2-GSK3beta cascade regulates Snaill activity in breast cancer cells. Nat Cell Biol 8: 1398-1406, 2006.

17. Rubinfeld B, Albert I, Porfiri E, Fiol C, Munemitsu S and Polakis P: Binding of GSK3beta to the APC-beta-catenin complex and regulation of complex assembly. Science 272: 1023-1026, 1996.

18. Aberle H, Bauer A, Stappert J, Kispert A and Kemler R: beta-catenin is a target for the ubiquitin-proteasome pathway. EMBO J 16: 3797-3804, 1997.

19. Liu C, Li Y, Semenov M, Han C, Baeg GH, Tan Y, Zhang Z, Lin X and $\mathrm{He} \mathrm{X}$ : Control of beta-catenin phosphorylation/degradation by a dual-kinase mechanism. Cell 108: 837-847, 2002.

20. van Noort M, Meeldijk J, van der Zee R, Destree O and Clevers H: Wnt signaling controls the phosphorylation status of beta-catenin. J Biol Chem 277: 17901-17905, 2002

21. Hino S, Tanji C, Nakayama KI and Kikuchi A: Phosphorylation of beta-catenin by cyclic AMP-dependent protein kinase stabilizes beta-catenin through inhibition of its ubiquitination. Mol Cell Biol 25: 9063-9072, 2005

22. Taurin S, Sandbo N, Qin Y, Browning D and Dulin NO Phosphorylation of beta-catenin by cyclic AMP-dependent protein kinase. J Biol Chem 281: 9971-9976, 2006.

23. Gwak J, Lee JH, Chung YH, Song GY and Oh S: Small molecule-based promotion of PKC $\alpha$-mediated $\beta$-catenin degradation suppresses the proliferation of CRT-positive cancer cells. PLoS One 7: e46697, 2012.

24. Habelhah H, Takahashi S, Cho SG, Kadoya T, Watanabe T and Ronai Z: Ubiquitination and translocation of TRAF2 is required for activation of JNK but not of p38 or NF-kappaB. EMBO J 23 : 322-332, 2004

25. Akimov IA, Chernolovskaya EL, Spitsyna YE, Ryabchikova EI and Zenkova MA: Silencing of Her2, CCNB1 and PKC Genes by siRNA Results in Prolonged Retardation of Neuroblastoma Cell Division. Acta Naturae 3: 29-39, 2011.

26. Jung JK, Kwun HJ, Lee JO, Arora P and Jang KL: Hepatitis B virus $X$ protein differentially affects the ubiquitin-mediated proteasomal degradation of beta-catenin depending on the status of cellular p53. J Gen Virol 88: 2144-2154, 2007.

27. Kim SJ, Glick A, Sporn MB and Roberts AB: Characterization of the promoter region of the human transforming growth factor-beta 1 gene. J Biol Chem 264: 402-408, 1989.

28. Lee Y, Kim SJ, Park HD, Park EH, Huang SM, Jeon SB, Kim JM, Lim DS and Koh SS: PAUF functions in the metastasis of human pancreatic cancer cells and upregulates CXCR4 expression. Oncogene 29: 56-67, 2010.

29. Liang CC, Park AY and Guan JL: In vitro scratch assay: A convenient and inexpensive method for analysis of cell migration in vitro. Nat Protoc 2: 329-333, 2007.
30. Mbom BC, Siemers KA, Ostrowski MA, Nelson WJ and Barth AI: Nek2 phosphorylates and stabilizes $\beta$-catenin at mitotic centrosomes downstream of Plk1. Mol Biol Cell 25: 977-991, 2014

31. Steinway SN, Zañudo JG, Ding W, Rountree CB, Feith DJ, Loughran TP Jr and Albert R: Network modeling of TGF $\beta$ signaling in hepatocellular carcinoma epithelial-to-mesenchymal transition reveals joint sonic hedgehog and Wnt pathway activation. Cancer Res 74: 5963-5977, 2014.

32. Nakagiri S, Murakami A, Takada S, Akiyama T and Yonehara S Viral FLIP enhances Wnt signaling downstream of stabilized beta-catenin, leading to control of cell growth. Mol Cell Biol 25: 9249-9258, 2005.

33. Ge X, Jin Q, Zhang F, Yan T and Zhai Q: PCAF acetylates \{beta\}-catenin and improves its stability. Mol Biol Cell 20: 419-427, 2009.

34. Mardin BR, Lange C, Baxter JE, Hardy T, Scholz SR, Fry AM and Schiebel E: Components of the Hippo pathway cooperate with Nek2 kinase to regulate centrosome disjunction. Nat Cell Biol 12: 1166-1176, 2010.

35. Das TK, Dana D, Paroly SS, Perumal SK, Singh S, Jhun H, Pendse J, Cagan RL, Talele TT and Kumar S: Centrosomal kinase Nek2 cooperates with oncogenic pathways to promote metastasis. Oncogenesis 2: e69, 2013.

36. Zhang X, Fan Q, Li Y, Yang Z, Yang L, Zong Z, Wang B, Meng X, Li Q, Liu J, et al: Transforming growth factor-betal suppresses hepatocellular carcinoma proliferation via activation of Hippo signaling. Oncotarget 8: 29785-29794, 2017.

37. Zhong X, Guan X, Liu W and Zhang L: Aberrant expression of NEK 2 and its clinical significance in non-small cell lung cancer. Oncol Lett 8: 1470-1476, 2014.

38. Lu L, Zhai X and Yuan R: Clinical significance and prognostic value of Nek2 protein expression in colon cancer. Int J Clin Exp Pathol 8: 15467-15473, 2015.

39. Liu H, Liu B, Hou X, Pang B, Guo P, Jiang W, Ding Q, Zhang R, Xin T, Guo H, et al: Overexpression of NIMA-related kinase 2 is associated with poor prognoses in malignant glioma. J Neurooncol 132: 409-417, 2017.

40. Liu X, Gao Y, Lu Y, Zhang J, Li L and Yin F: Upregulation of NEK2 is associated with drug resistance in ovarian cancer. Oncol Rep 31: 745-754, 2014.

41. Coxon CR, Wong C, Bayliss R, Boxall K, Carr KH, Fry AM, Hardcastle IR, Matheson CJ, Newell DR, Sivaprakasam M, et al: Structure-guided design of purine-based probes for selective Nek2 inhibition. Oncotarget 8: 19089-19124, 2017.

42. Xi JB, Fang YF, Frett B, Zhu ML, Zhu T, Kong YN, Guan FJ, Zhao Y, Zhang XW, Li HY, et al: Structure-based design and synthesis of imidazo[1,2-a]pyridine derivatives as novel and potent Nek 2 inhibitors with in vitro and in vivo antitumor activities. Eur J Med Chem 126: 1083-1106, 2017.

43. Frett B, Brown RV, Ma M, Hu W, Han H and Li HY: Therapeutic melting pot of never in mitosis gene a related kinase 2 (Nek2): A perspective on Nek2 as an oncology target and recent advancements in Nek2 small molecule inhibition. J Med Chem 57: 5835-5844, 2014.

44. Lee JH, Kim MA, Park S, Cho SH, Yun E, O YS, Kim J, Goo JI, Yun MY, Choi Y, et al: Synthesis and evaluation of (+)-decursin derivatives as inhibitors of the Wnt/ $\beta$-catenin pathway. Bioorg Med Chem Lett 26: 3529-3532, 2016.

45. Zhang Y, Shaik AA, Xing C, Chai Y, Li L, Zhang J, Zhang W, Kim SH, Lü J and Jiang C: A synthetic decursin analog with increased in vivo stability suppresses androgen receptor signaling in vitro and in vivo. Invest New Drugs 30: 1820-1829, 2012.

This work is licensed under a Creative Commons Attribution-NonCommercial-NoDerivatives 4.0 International (CC BY-NC-ND 4.0) License. 